\title{
Eficiência da estação de tratamento de efluentes do Município de Corrente, Estado do Piauí, Nordeste do Brasil
}

\section{Estéfani Barros Maciel $^{1}{ }^{*}$, Marcília Martins da Silva², Luana de Castro Pereira ${ }^{1}$, Luzirany Soares Lopes ${ }^{1}$, Cecília de Souza Carvalho ${ }^{1}$, Raiane Oliveira de Souza $^{1}$ e Patrine Nunes Gomes ${ }^{1}$}

${ }^{1}$ Instituto Federal de Educação, Ciência e Tecnologia do Piauí. Curso de Graduação em Tecnologia em Gestão Ambiental. Campus Corrente. Rua Joaquin Reis, 75. Centro. São Gonçalo do Gurgueia-PI, Brasil (CEP 64993-000). *E-mail: estefanibarrosmaciel@gmail.com.

${ }^{2}$ Instituto Federal de Educação, Ciência e Tecnologia do Piauí. Campus Corrente. Rua Projetada 6. Nova Corrente. Corrente-PI, Brasil (CEP 64980-000).

Resumo. Atualmente o crescimento populacional e o desenvolvimento de novas atividades têm aumentado a demanda ao uso da água, recurso fundamental à vida, e seu uso-doméstico pode influenciar no aumento da geração de efluentes, que quando não tratados corretamente afetam diretamente a qualidade socioambiental. Neste sentido, a fim de assegurar a disponibilidade da água aos presentes e futuras gerações, tornase de grande valia manter a qualidade de vida nos grandes centros urbanos, e, além disso, reduzir os impactos ambientais em decorrência das ações antrópicas, cabendo aos órgãos governamentais buscar fins que proporcionem a qualidade para o lançamento correto dos efluentes em corpos hídricos. Visto isso, o presente estudo objetivou analisar a eficiência da Estação de Tratamento de Efluentes do Município de Corrente, Estado do Piauí, Nordeste do Brasil. As coletas foram efetuadas em abril de 2019, durante período chuvoso. As variáveis analisadas foram oxigênio dissolvido, demanda bioquímica de oxigênio, amônia, nitrito, nitrato, fósforo total, coliformes totais, temperatura e $\mathrm{pH}$. Com base nos resultados obtidos, observou-se que temperatura, amônia, nitrito, nitrato, oxigênio dissolvido, demanda bioquímica de oxigênio e pH estão de acordo com os padrões estabelecido nas resoluções do Conselho Nacional de Meio Ambiente (CONAMA). Fósforo e coliformes não apresentaram valores adequados que permitam que os efluentes sejam lançados no corpo receptor (Rio Corrente). Conclui-se assim que apesar da estação possuir eficiência na maioria das variáveis analisadas, há a necessidade de melhorar sua estrutura, com finalidade de atender toda a população urbana. Bem como seria de suma importância que o município possuísse um sistema de coleta separativo, no intuito
Recebido

$21 / 05 / 2020$

Aceito

$26 / 07 / 2021$

Disponível on line

$31 / 07 / 2021$

Publicado

$31 / 08 / 2021$

Acesso aberto

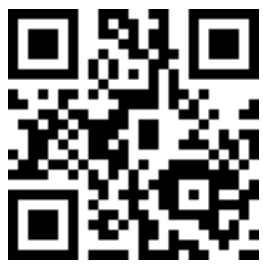

ORCID

(ㄱ) 0000-0001-9456-5915 Estéfani Barros Maciel (D) 0000-0002-4906-7965 Marcília Martins da Silva 
de apartar as águas pluviais do esgotamento sanitário, a fim de obter maior eficiência do tratamento no período chuvoso.

Palavras-chave: Esgotamento sanitário; Impactos ambientais; Período chuvoso.

Abstract. Efficiency of the effluent treatment plant in the Corrente, State of Piauí, Northeastern Brazil Currently, population growth and the development of new activities have increased the demand for the use of water, a fundamental resource for life, and its domestic use can influence the increase in the generation of effluents, which, when not treated correctly, directly affect socio-environmental quality. In this sense, in order to ensure the availability of water for present and future generations, it is of great value to maintain the quality of life in large urban centers, and, in addition, to reduce the environmental impacts resulting from anthropic actions, government agencies seek purposes that provide the quality for the correct release of effluents into water bodies. In view of this, this study aimed to analyze the efficiency of the effluent treatment plant in the Municipality of Corrente, State of Piauí, Northeastern Brazil. Collections were carried out in April 2019, during the rainy season. The analyzed variables were dissolved oxygen, biochemical oxygen demand, ammonia, nitrite, nitrate, total phosphorus, total coliforms, temperature and $\mathrm{pH}$. Based on the results obtained, it was observed that temperature, ammonia, nitrite, nitrate, dissolved oxygen, biochemical oxygen demand and $\mathrm{pH}$ are in accordance with the standards established in the resolutions of the Brazilian National Environmental Council (CONAMA). Phosphorus and coliforms did not show adequate values that allow effluents to be released into the receiving body (River Corrente). Thus, it is concluded that despite the station having efficiency in most of the analyzed variables, there is a need to improve its structure, in order to serve the entire urban population. As well, it would be extremely important that the municipality had a separate collection system, in order to separate the rainwater from the sanitary sewage, in order to obtain greater efficiency in the treatment during the rainy season.

Keywords: Sanitary sewage; Environmental impacts; Rainy season.

\section{Introdução}

Atualmente, o crescimento populacional e o desenvolvimento de novas atividades têm aumentado a demanda no que se refere ao uso da água, recurso esse que é considerado fundamental à vida e alguns de seus usos, como o doméstico, pode influenciar no aumento da geração de efluentes, que quando não tratados de maneira correta afetam diretamente a qualidade socioambiental.

Em decorrência do crescimento populacional e devido às demandas industriais e agrícolas, o uso da água pelos seres humanos tem provocado inúmeros questionamentos
0000-0001-8814-0478

Pereira

(D) 0000-0003-1698-1029

D) 0000-0003-1362-4077

Cecília de Souza

Carvalho

D 0000-0003-3116-115X

Raiane Oliveira de

Souza

(D) 0000-0002-9201-6928

Patrine Nunes Gomes
Luana de Castro

Luzirany Soares Lopes 
na sociedade, sendo um deles as emissões de efluentes em corpos hídricos causadas por atividades antrópicas, quando esses são lançados de forma inadequada, causando prejuízos à saúde dos seres vivos e ao meio ambiente (Silva e Oliveira, 2016).

Os efluentes são definidos como resíduos provenientes de redes pluviais, industriais e esgotos domésticos em forma de líquidos ou gases que podem contaminar tanto o solo como o lençol freático, os rios, o ar pela emissão de odores desagradáveis e entre outros (Brasil, 2011).

Dentre os diversos tipos de uso da água, sejam eles diretos ou indiretos, há uma grande necessidade de preservação e recuperação desses recursos, que a cada dia vem se tornando mais evidente. 0 lançamento de efluentes é uma das principais ameaças para os recursos hídricos, um problema mundial, seu controle é considerado um dos grandes desafios para a gestão dos recursos hídricos, não só no Brasil, mas no mundo (Teodoro et al., 2013).

Tendo em vista que o lançamento de efluentes é uma das principais preocupações para ambientalistas, por esses, quando lançados de modo indevido nos corpos hídricos, causarem impactos negativos ao meio ambiente e à saúde da população, torna-se necessário a ampliação de uma rede coletora e das estações de tratamento de efluentes (ETE) (Salgado e Araújo, 2017).

Uma análise de dados no âmbito nacional mostra que somente $51,92 \%$ das residências brasileiras tem coleta de esgoto e que, desse total, apenas 44,92\% dos esgotos recebem algum tipo de tratamento. Como consequência, uma grande parte destes efluentes que não adquire nenhum tipo de tratamento adequado são despejados in natura todos os dias, influenciando de forma negativa os recursos hídricos a vida animal, vegetal e a saúde humana (Instituto Trata Brasil, 2018).

0 despejo de esgotos nos rios sem o devido tratamento é um problema tanto ambiental, quanto social e de saúde pública, pois esses são responsáveis pela morte de seres aquáticos, diminuição da vazão do corpo hídrico, bem como pode provocar doenças que são transmitidas pelo contato direto com o corpo hídrico contaminado (Instituto Trata Brasil, 2018).

As águas residuárias necessitam de tratamento antes de serem lançadas diretamente nos corpos hídricos, evitando dessa maneira a contaminação do corpo receptor, a proliferação de doenças e proporcionando melhor qualidade de vida. Portanto, tal tratamento é de suma importância para a saúde humana e para o meio ambiente. 0 destino adequado dessas águas traz conforto estético, promoção dos hábitos de higiene da população, evita propagação de doença e vetores, preserva os mananciais e reduz custos com o tratamento de água (Pires et al., 2015).

Neste sentido, a fim de assegurar a disponibilidade da água às presentes e futuras gerações, torna-se de grande valia manter a qualidade de vida nos grandes centros urbanos e além disso reduzir os impactos ambientais em decorrência das ações antrópicas, cabendo aos órgãos governamentais buscar fins que proporcionem a qualidade para o lançamento correto dos efluentes em corpos hídricos. Visto isso, o presente estudo objetivou analisar a eficiência da estação de tratamento de efluentes (ETE), do Município de Corrente-PI.

\section{Metodologia}

\section{Área de estudo}

O presente trabalho foi realizado no Município de Corrente Piauí, localizado na faixa extremo sul do Estado do Piauí (Figura 1), com coordenadas de referência de latitude $10^{\circ} 26^{\prime} 30^{\prime \prime} \mathrm{S}$ e longitude $45^{\circ} 09^{\prime} 52^{\prime \prime} \mathrm{W}$, em elevação de $443 \mathrm{~m}$ acima do nível do mar, com área territorial de $3.048,447 \mathrm{~km}^{2}$, a uma distância de $836,3 \mathrm{~km}$ da Capital Teresina. 0 
município possui uma população urbana estimada de 26. 084 habitantes e está localizado no bioma cerrado (IBGE, 2015).

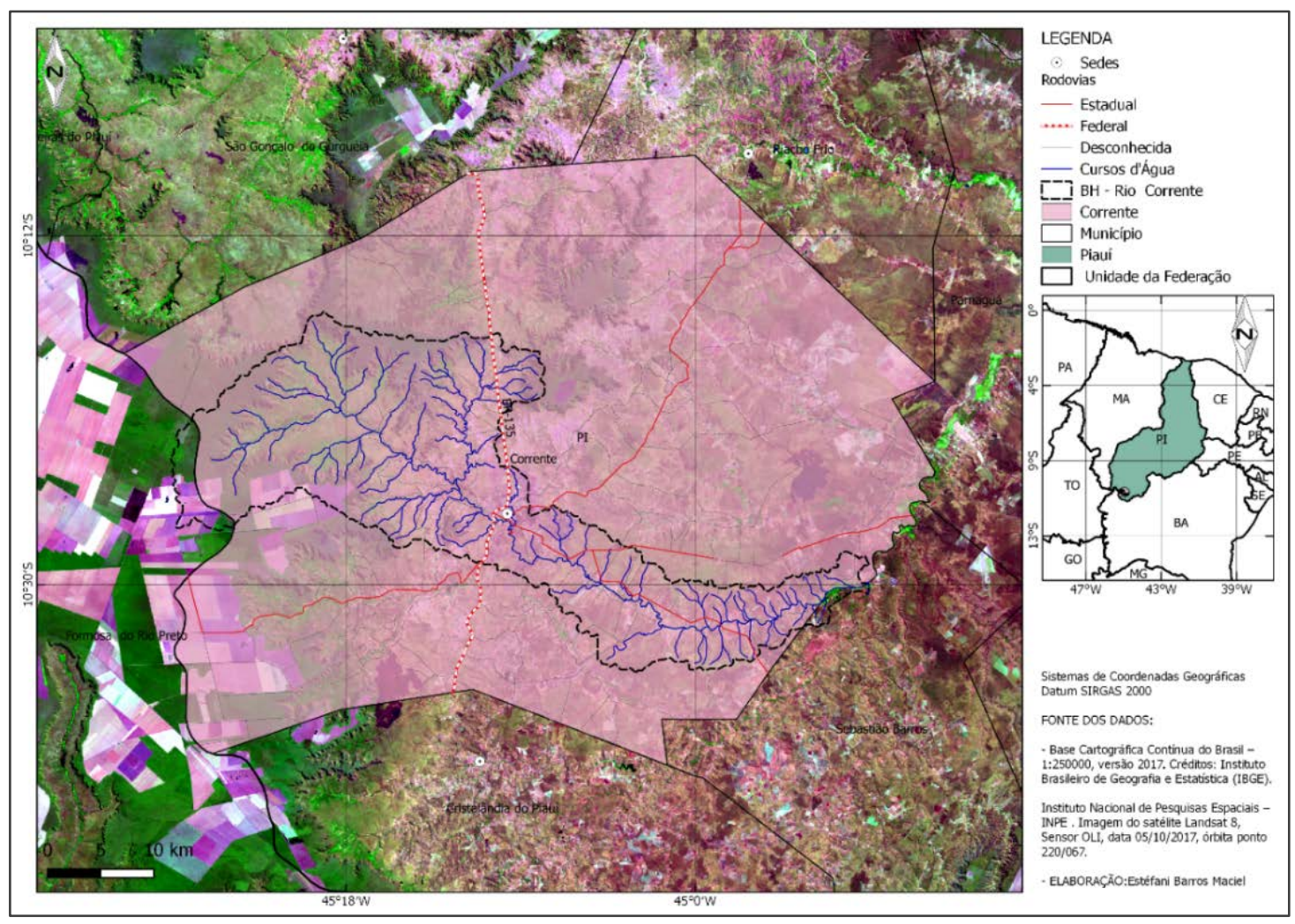

Figura 1. Mapa de Localização do Município de Corrente-PI.

O Município de Corrente-PI apresenta clima tropical sub úmido (IBGE 2015) e as temperaturas máximas anuais $31,6{ }^{\circ} \mathrm{C}$, mínimas de $19,3{ }^{\circ} \mathrm{C}$ e a média de $25,4{ }^{\circ} \mathrm{C}$, já precipitação pluviométrica anual na sede é $1.064,7 \mathrm{~mm}$ (Medeiros et al., 2014).

A estação de tratamento é responsável por tratar os efluentes gerados na cidade para que desse modo possam ser lançados no corpo hídrico sem causar danos à saúde das pessoas e ainda causar danos ambientais (Brasil, 2011)

O Rio Corrente é considerado, segundo a Resolução CONAMA no 357/2005 (Brasil, 2005), como de classe 2. Essa classificação foi baseada no art. 42, da referida resolução, que diz que "enquanto não aprovados os respectivos enquadramentos, as águas doces serão consideradas Classe 2".

\section{Procedimentos metodológicos}

Para a obtenção dos resultados foram executadas visitas in loco, para melhor evidenciar a área. Foi realizada ainda coleta de coordenadas geográficas por meio do GPS e utilizou-se o QGIS desktop 2.14.8, para confecção do mapa de localização da área e ainda foram feitos registros fotográficos para melhor evidenciar a área de estudo.

Foram coletadas amostras nas lagoas de tratamento de efluente durante o período chuvoso. Posteriormente estas foram acondicionadas em uma caixa térmica e preservadas conforme o Guia Nacional de Coleta e Preservação de Amostras de Água (CETESB e ANA, 2016). Logo após as coletas as amostras foram encaminhadas para análise no Laboratório 
de Biologia, Solos e Água, após as análises os dados encontrados foram confrontados com os padrões determinados na Resolução CONAMA no 357/2005 (Brasil, 2005) na Resolução CONAMA no 430/2011 (Brasil, 2011).

As coletas foram efetuadas no mês de abril de 2019, período esse chuvoso, que foi escolhido para a avaliação por receber uma maior quantidade de efluentes, sendo que o sistema de coleta do Município Corrente é um sistema unitário, ou seja, possui uma mesma rede coletora tanto para efluentes domésticos quanto para as águas pluviais, e nesse período as estações tendem a receber uma maior quantidade de esgoto, influenciando na sua eficiência, pois ela não suporta nesse período a demanda e chega ao extravasamento das lagoas.

As variáveis analisadas foram oxigênio dissolvido, demanda bioquímica de oxigênio, amônia, nitrito, nitrato, fósforo total, coliformes totais, temperatura e pH. Essa análise permite saber se a estação consegue realizar com eficiência o tratamento adequado do efluente e se pode ser lançado, após tratamento, diretamente no corpo hídrico, respeitando os parâmetros exigidos para esse tipo de rio (Brasil, 2011). Para a avaliação desses parâmetros foi necessário o uso dos seguintes materiais.

E para calcular a porcentagem e eficiência da remoção do poluente, empregou-se o modelo proposto por Von Sperling (2014), o qual está expresso na Equação 1 para analisar a melhor forma de disposição do efluente tratado, tomou-se como referência a Resolução CONAMA no 357/2005 (Brasil, 2005) e a Resolução CONAMA no 430/2011 (Brasil, 2011), a qual estabelece as condições e padrões para o lançamento de efluentes em corpos d'água.

$$
E=\frac{C_{0}-C_{e} \times 100}{C_{0}}
$$

\section{Pontos de amostragem}

Para a realização do trabalho foram selecionados quatro pontos de amostragem dentro da ETE, o ponto de amostragem 1 é o esgoto que chega através da rede coletora para avaliação do Esgoto Bruto (EB) o Ponto 2 corresponde a lagoa facultativa (LF) e o ponto 3 e 4 são as lagoas de maturação (LM), como mostra o (Figura 2).

0 procedimento da lagoa facultativa é realizado pelas bactérias aeróbias e anaeróbias existentes no próprio esgoto, as quais depuram o efluente preparando esse para a próxima etapa que são as lagoas de maturação (Melo Júnior et al., 2018).

As lagoas de maturação possuem a função de remoção de microrganismos patogênicos. Nestas lagoas predominam condições ambientais adversas para bactérias patogênicas, como radiação ultravioleta, elevado $\mathrm{pH}$, elevada concentração de oxigênio dissolvido, temperaturas baixas e ausência de nutrientes, na qual essas reduzem as bactérias, sólidos em suspensão, nutrientes e uma parcela da demanda bioquímica de oxigênio, responsável também pela remoção de coliformes (Barthel, 2007).

Como mostra Figura 2, a estação de tratamento de efluentes (ETE) do Município de Corrente-PI possui três lagoas, sendo que a lagoa 1 é facultativa, a que recebe todo o efluente bruto, lagoa 2 e 3 de maturação. 

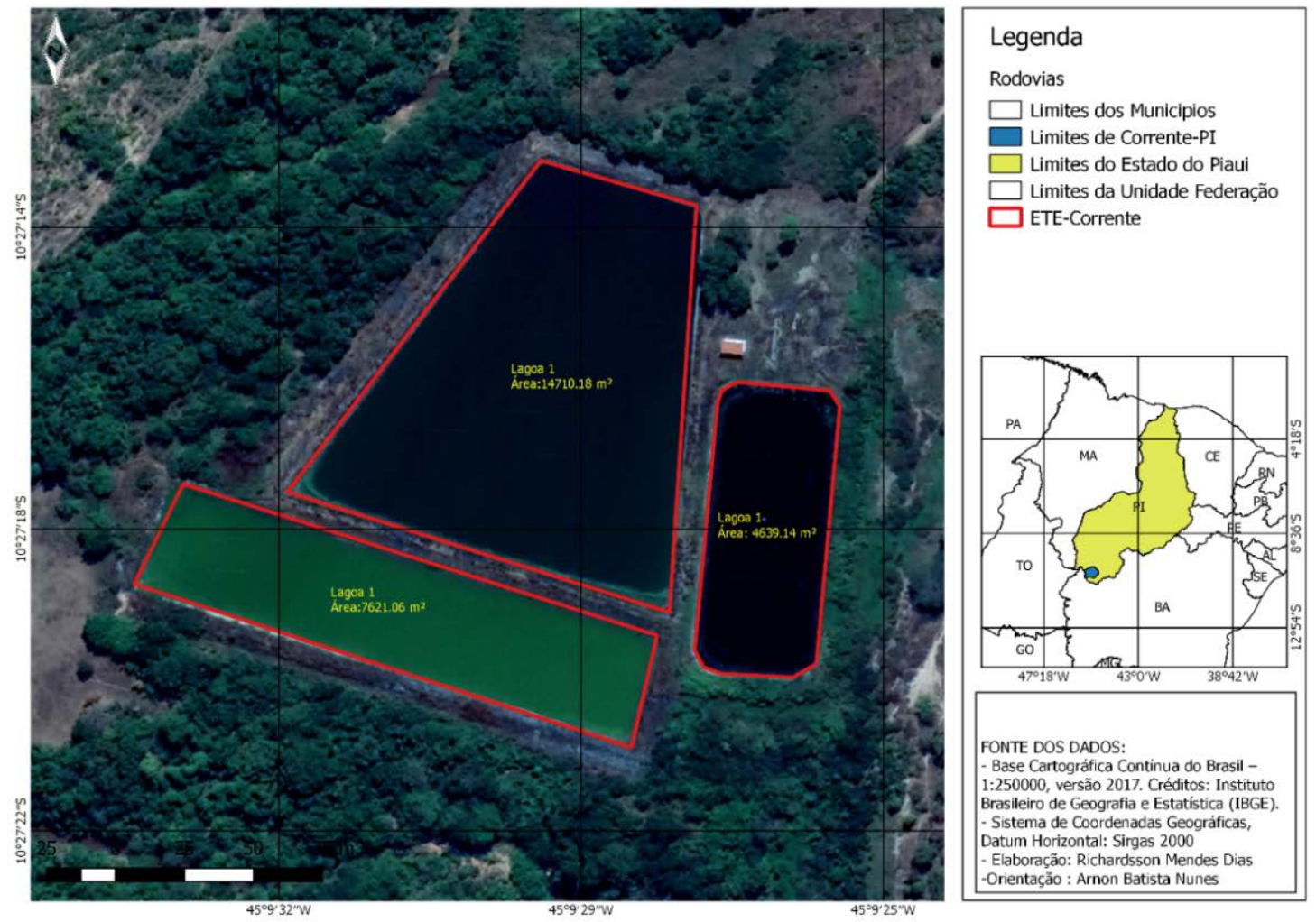

Figura 2. Localização espacial da Estação de Tratamento de Esgoto, Corrente-PI. 2017.

\section{Resultados e discussão}

\section{Análise da infraestrutura da estação de tratamento de efluentes}

A Estação de Tratamento de Efluentes (ETE) do Município de Corrente-PI possui uma estrutura básica, sendo um gradeamento, onde materiais grosseiros ficam retidos; decantadores, sendo que é retirado à parte de areia e outros materiais e logo após o esgoto passam por três lagoas.

Nas lagoas, o esgoto passa por um processo de estabilização, sendo que ocorre apenas o processo fotossintético, ou seja, na primeira lagoa facultativa e na segunda e terceira lagoa de maturação o esgoto é tratado apenas por procedimentos biológicos, onde bactérias anaeróbias são usadas na degradação da matéria orgânica, chegando ao final do tratamento ainda com uma carga poluidora muito alta, vindo a poluir o rio que abastece a cidade e outras comunidades.

De acordo com o Relatório de Esgotamento Sanitário Municipal (2017), a estação de tratamento existente possui procedimentos constituídos por lagoas facultativas e lagoas de maturação. De um total de 16.014 habitantes na área urbana a estação atende apenas 3.906 habitantes, esse mesmo relatório mostra que a eficiência da estação é de $80 \%$.

Analisando esses dados percebe-se que, a estação atende uma pequena parcela da população e, além disso, o relatório possui falhas no que diz respeito ao tipo de procedimento adotado para o tratamento do efluente.

Esse mesmo relatório faz uma previsão de quantos habitantes terá a cidade no ano de 2035 e a população estimada é de 20.446 habitantes na zona urbana sendo que a população atendida será de 20.446 habitantes, sendo assim, todos os habitantes serão atendidos e nesse período a eficiência da estação está prevista para 90\%, no entanto, para condições atuais de infraestrutura a ETE não conseguirá atender a essa demanda. 
Todo o esgoto que chega na ETE passa pelo tratamento primário que é composto por gradeamento e caixas de areia. A grade é feita de chapas de aço de seção retangular e tem o objetivo de reter o material grosseiro tais como plástico, folhas e etc. e as caixas de retenção de areia tem a finalidade de remoção de solos do efluente.

Os tipos de lagoa da ETE do Município de Corrente são lagoas facultativa (primeira no processo de tratamento) seguida de duas lagoas de maturação onde o tratamento é feito por etapas sendo que o efluente que chega à estação passa por três lagoas e só depois esse efluente é lançado no corpo hídrico. Após passar pela sequência de lagoas os efluentes tratados estão prontos para serem lançados no corpo receptor.

\section{Análise do efluente}

Constatou-se que o efluente ao final do processo de tratamento não se apresentou dentro dos padrões determinados pela Resolução CONAMA no 430/2011 (Brasil, 2011). Sendo que todos os parâmetros deveriam estar de acordo com a norma vigente contendo assim o mínimo possível de carga poluidora antes de serem lançados no corpo receptor (Rio Corrente), sem maiores impactos a população e ao meio.

Os resultados foram confrontados com os padrões determinados pela Resolução CONAMA no 357/2005 (Brasil, 2005) e a pela Resolução CONAMA no 430/2011 (Brasil, 2011). Observou-se que temperatura, amônia, nitrito, nitrato, oxigênio dissolvido, demanda bioquímica de oxigênio e pH estão dentro dos padrões estabelecidos por essas normas. No que diz respeito aos padrões de fósforo e coliformes totais obteve-se um resultado muito acima do determinado pelas resoluções.

As inconformidades das variáveis analisadas com os parâmetros determinados na legislação para o lançamento do efluente no corpo receptor podem estar associadas diretamente às falhas na infraestrutura da estação de tratamento, tendo como exemplo a ausência de manutenção, monitoramento e investimentos. A partir do momento em que o tratamento do efluente é constituído apenas por um procedimento (fotossintético), o resultado final pode estar sujeito a possuir uma gama de problemas.

As Estações de Tratamento de Efluentes (ETE's) deveriam possuir todos os tipos de tratamentos adequados, sendo eles o tratamento preliminar, primário, secundário e terciário (Barbosa 2018). No entanto, a estação de tratamento do Município de Corrente possui apenas tratamento preliminar, primário e secundário, com isso os problemas começam a surgir a partir do momento em que os efluentes são lançados nas lagoas. Por se tratar de uma estação de estrutura pequena, a quantidade de efluente que chega até as lagoas é maior que a sua capacidade de armazenamento, isso devido ela não ter acompanhado o crescimento populacional do município.

No Município de Corrente-PI, apenas $11,6 \%$ dos domicílios estão ligados à rede coletora de esgoto (IBGE, 2010). Esse percentual representa os 3.906 domicílios que são atendidos com o sistema coleta de esgoto, isso de acordo o Relatório de Esgotamento Sanitário Municipal de Corrente (RESMC, 2017). No entanto, a quantidade total de residências no município é 10.293 de acordo com informações obtidas pessoalmente no escritório da Companhia Energética do Piauí (CEPISA).

Quando este percentual é comparado com os municípios da microrregião, o Município de Corrente fica na $1^{\circ}$ posição de nove, com relação aos outros municípios do estado, ocupa a posição $100^{\circ}$ de 224. Quando comparado aos outros municípios do Brasil, a posição é 4.235을 5570 (IBGE, 2010).

A ETE do Município de Corrente não está em conformidade com a resolução vigente, e sua inconformidade pode ocasionar sérios danos tanto para meio ambiente quanto para a saúde, e ao verificar a sua eficiência foi possível fazer comparações pós analises com a Resolução no CONAMA 430/2011 e a Resolução no 357/2005 (que dispõe dos parâmetros necessários para despejo de efluentes em corpos d'água). 
Para a Lagoa de Maturação 2 (LM 2) que consiste na última etapa do tratamento no qual o efluente se encontra, supostamente, pronto para ser lançado no corpo receptor, obteve-se os seguintes valores para os parâmetros analisados: temperatura $24^{\circ} \mathrm{C}$, amônia de $0,22 \mathrm{mg} / \mathrm{L}$, nitrito $0,02 \mathrm{mg} / \mathrm{L}$, nitrato $1,22 \mathrm{mg} / \mathrm{L}$, oxigênio dissolvido $8,2 \mathrm{mg} / \mathrm{L}, \mathrm{pH} 7 \mathrm{e}$ DBO de $50 \mathrm{mg} / \mathrm{L}$, todos dentro dos padrões da Resolução CONAMA no 430/2011 e da Resolução CONAMA no 357/2005, estão de acordo para o padrão de eficiência de uma ETE, no entanto, o valor do fósforo foi de $6,83 \mathrm{mg} / \mathrm{L}$, e coliformes de $9.280 \mathrm{mg} / \mathrm{L}$, sendo que esses não estão em conformidade com o estabelecido pela resolução vigente (Tabela 1).

Tabela 1. Análise das amostras durante período chuvoso.

\begin{tabular}{|l|c|c|c|c|c|}
\hline Variáveis & $\begin{array}{c}\text { Ponto 1 } \\
\text { Efluente } \\
\text { bruto }\end{array}$ & $\begin{array}{c}\text { Ponto 2 } \\
\text { Lagoa } \\
\text { facultativa }\end{array}$ & $\begin{array}{c}\text { Ponto 3 } \\
\text { Lagoa de } \\
\text { maturação 1 }\end{array}$ & $\begin{array}{c}\text { Ponto 4 } \\
\text { Lagoa de } \\
\text { maturação 2 }\end{array}$ & $\begin{array}{c}\text { Resolução } \\
\text { CONAMA no } \\
\mathbf{4 3 0 / 2 0 1 1 ~ e ~} \\
\mathbf{3 5 7} / 2005\end{array}$ \\
\hline Temperatura & $27,8{ }^{\circ} \mathrm{C}$ & $25,7{ }^{\circ} \mathrm{C}$ & $24,4{ }^{\circ} \mathrm{C}$ & $24,0{ }^{\circ} \mathrm{C}$ & $<40{ }^{\circ} \mathrm{C}$ \\
\hline Amônia & $1,83 \mathrm{mg} / \mathrm{L}$ & $0,04 \mathrm{mg} / \mathrm{L}$ & $1,91 \mathrm{mg} / \mathrm{L}$ & $0,22 \mathrm{mg} / \mathrm{L}$ & $<5,0 \mathrm{mg} / \mathrm{L}$ \\
\hline Nitrito & $0,03 \mathrm{mg} / \mathrm{L}$ & $0,02 \mathrm{mg} / \mathrm{L}$ & $0,03 \mathrm{mg} / \mathrm{L}$ & $0,02 \mathrm{mg} / \mathrm{L}$ & $<1,0 \mathrm{mg} / \mathrm{L}$ \\
\hline Nitrato & $1,75 \mathrm{mg} / \mathrm{L}$ & $1,02 \mathrm{mg} / \mathrm{L}$ & $1,83 \mathrm{mg} / \mathrm{L}$ & $1,22 \mathrm{mg} / \mathrm{L}$ & $<10,0 \mathrm{mg} / \mathrm{L}$ \\
\hline Fósforo & $11,78 \mathrm{mg} / \mathrm{L}$ & $3,86 \mathrm{mg} / \mathrm{L}$ & $8,48 \mathrm{mg} / \mathrm{L}$ & $6,83 \mathrm{mg} / \mathrm{L}$ & $<1,0 \mathrm{mg} / \mathrm{L}$ \\
\hline Coliformes & $2.320 \mathrm{mg} / \mathrm{L}$ & $1.280 \mathrm{mg} / \mathrm{L}$ & $10.480 \mathrm{mg} / \mathrm{L}$ & $9.280 \mathrm{mg} / \mathrm{L}$ & $<1.000 \mathrm{mg} / \mathrm{L}$ \\
\hline OD & $9,8 \mathrm{mg} / \mathrm{L}$ & $9,5 \mathrm{mg} / \mathrm{L}$ & $8,4 \mathrm{mg} / \mathrm{L}$ & $8,2 \mathrm{mg} / \mathrm{L}$ & $>5,0 \mathrm{mg} / \mathrm{L}$ \\
\hline DBO & $30 \mathrm{mg} / \mathrm{L}$ & $120 \mathrm{~m} / \mathrm{L}$ & $110 \mathrm{mg} / \mathrm{L}$ & $50 \mathrm{mg} / \mathrm{L}$ & $<120 \mathrm{mg} / \mathrm{L}$ \\
\hline pH & 7,0 & 9,0 & 6,0 & 7,0 & $66 \mathrm{a} 9$ \\
\hline
\end{tabular}

Como mostra a Tabela 1, o tratamento do efluente da estação não está sendo totalmente eficaz para os parâmetros fósforo e coliformes totais que ao serem lançados sendo lançados de forma inadequada no corpo hídrico, podem causar uma série de impactos negativos para o meio e a saúde humana.

0 fósforo quando se encontra em excesso são responsáveis por diversos problemas ambientais, tais como a eutrofização de corpos d'água a mortalidade dos seres aquáticos e até mesmo problemas relacionados à saúde humana, dessa maneira é importante controlar a sua concentração para assim evitar tais problemas (Gerhardt et al., 2018).

A concentração de fósforo presentes no efluente bruto foi de $11,78 \mathrm{mg} / \mathrm{L}$, na lagoa 1 foi 3,86 mg/L, mostrando também uma eficiência considerável por ser ainda a primeira lagoa, já no que se refere a lagoa 2 foi possível constatar um aumento considerável de $8,48 \mathrm{mg} / \mathrm{L}$ nesse caso o tratamento da lagoa 2 não está realizando seu trabalho com eficiência, pois o teor de fósforo aumentou significativamente em relação a lagoa 1. Já na última lagoa o teor de fósforo reduziu quando comparada com a segunda, onde apresentou um valor de $6,83 \mathrm{mg} / \mathrm{L}$, mas, ainda assim continuando em desacordo com a resolução.

De acordo com os dados apresentados na tabela os teores médios de fósforo em uma ETE tem que estar de acordo com a Resolução vigente, ou seja, tem que ser menor ou igual a 1,0 mg/L. E no que se refere a competência do tratamento da estação de esgoto sobre o referido parâmetro, pôde-se constatar que o tratamento não é realizado com eficiência.

Com relação aos coliformes totais, são grandes a quantidade dos indicadores de contaminação fecal que podem ocasionar problemas tanto para o meio ambiente quanto para a saúde. 
A concentração de coliformes totais presentes no efluente bruto foi de $2.320 \mathrm{mg} / \mathrm{L}$, na lagoa 1 foi de $1.280 \mathrm{mg} / \mathrm{L}$, mostrando assim eficiência até então, já a lagoa 2 mostra uma alta taxa no que se refere a esse parâmetro de $10.480 \mathrm{mg} / \mathrm{L}$ aumentando assim significativamente e mostrando que a lagoa 2 não apresenta uma boa eficiência no seu tratamento. Na última lagoa, essa taxa de coliformes cai para $9.280 \mathrm{mg} / \mathrm{L}$, mostrando que a lagoa 3 não elimina as bactérias o suficiente para que os efluentes tenham condições de serem lançados em corpos hídricos de classe 2.

De acordo os resultados obtidos, observa-se que o tratamento das lagoas não apresentou nenhuma diferença significativa na eliminação de coliformes totais, onde isso possivelmente pode estar relacionado com a dimensão das lagoas e com a quantidade de efluentes que chegam. De acordo Mataruco et al. (2019), "essa ineficiência no processo se dá devido ao mal dimensionamento das lagoas que recebem os efluentes, sendo pequenas para o grande volume de efluentes lançados".

Os principais impactos ambientais do Rio Corrente são a retirada da vegetação nas áreas de preservação permanente (APP's) e o lançamento de efluentes sem o tratamento adequado. A Resolução CONAMA nº 001/1986 (Brasil, 1986), considera impacto ambiental:

Qualquer alteração das propriedades físicas, químicas e biológicas do meio ambiente, causada por qualquer forma de matéria ou energia resultante das atividades humanas que, direta ou indiretamente, afetam: a saúde, a segurança e o bem-estar da população; as atividades sociais e econômicas; a biota; as condições estéticas e sanitárias do meio ambiente e a qualidade dos recursos ambientais (Brasil, 1986).

Esses problemas afetam o meio ambiente, a saúde das pessoas, e ainda a qualidade de vida afetando diretamente no desenvolvimento socioeconômico, devido ao aumento das fontes de contaminação, alteração dos corpos hídricos e diminuição de sua qualidade e dificultando o seu acesso (Tundisi e Matsumara-Tundisi, 2011).

No que se refere aos resultados das análises do afluente (esgoto bruto) e efluente (Esgoto tratado) para eficiência da ETE do Município de Corrente-PI, conforme Tabela 2, de maneira geral, o sistema de tratamento adotado se mostrou eficiente para a remoção de poluentes orgânicos, contudo, foi insatisfatório na remoção de fósforo e coliformes.

Tabela 2. Resultados nas análises físicas e químicas do afluente e efluente da ETE.

\begin{tabular}{|l|c|c|c|c|}
\hline \multirow{2}{*}{ Variável } & \multicolumn{2}{|c|}{ Resultados } & \multirow{2}{*}{ Unidade } & \multirow{2}{*}{ Eficiência (\%) } \\
\cline { 2 - 3 } & Afluente & Efluente & & 87,97 \\
\hline Amônia & 1,83 & 0,22 & $\mathrm{mg} / \mathrm{L}$ & 33,33 \\
\hline Nitrito & 0,03 & 0,02 & $\mathrm{mg} / \mathrm{L}$ & 30,28 \\
\hline Nitrato & 1,75 & 1,22 & $\mathrm{mg} / \mathrm{L}$ & 42,02 \\
\hline Fósforo & 11,78 & 6,83 & $\mathrm{mg} / \mathrm{L}$ & -300 \\
\hline Coliformes & 2.320 & 9.280 & $\mathrm{mg} / \mathrm{L}$ & 16,32 \\
\hline OD & 9,8 & 8,2 & $\mathrm{mg} / \mathrm{L}$ & $-66,66$ \\
\hline DBO & 30 & 50 & $\mathrm{mg} / \mathrm{L}$ & \\
\hline
\end{tabular}

Legenda: Afluente (esgoto bruto); efluente (esgoto tratado).

A carga de coliformes e DBO no afluente são menores do que no efluente, portanto, o sistema de tratamento adotado não possui nenhuma eficiência para a remoção desses poluentes. Sendo que a DBO, mesmo com essa ineficiência no que se refere ao tratamento 
do efluente bruto, comparando com a última etapa do tratamento da estação, encontra-se de acordo com o padrão estabelecido pela Resolução CONAMA no 430/2011 (Brasil, 2011) para lançamentos em corpos hídricos de classe 2.

No que se refere à eficiência da ETE na remoção do fósforo, essa possui uma efetividade de $42,2 \%$, no entanto quando se comparado ao valor máximo estabelecido pela resolução vigente, esse parâmetro não está adequado para lançamentos em corpos hídricos, dessa forma importante ressaltar a correção para tratamento desse parâmetro, pois a alta quantidade de fosforo pode causar o processo de eutrofização. Para Dias et al. (2016), o "efluente lançado deve satisfazer, tanto ao padrão de lançamento, quanto ao padrão de qualidade do corpo receptor segundo a sua classe".

A Equação 1, eficiência da remoção do poluente, não é aplicada para a variável pH e temperatura. Em se tratando dos outros valores como esses já estavam dentro dos parâmetros estabelecidos por lei, à eficiência deu baixa, pois não há uma grande diferença entre os valores do afluente com o efluente da última lagoa.

Constatou-se ainda que para os parâmetros que remetem a nitrogênio (amônia, nitrito e nitrato) estavam dentro dos padrões da Resolução CONAMA [qual resolução?], pois se lançados em não conformidade no corpo receptor poderia ocasionar no consumo de oxigênio dissolvido do meio, podendo afetando a vida aquática do recurso hídrico receptor (Esteves, 2011).

\section{Considerações finais}

Observou-se que em se tratando dos parâmetros como temperatura, amônia, nitrito, nitrato, oxigênio dissolvido, demanda bioquímica de oxigênio (DBO) e pH, estes estão em acordo com a Resolução CONAMA no 357/2005 (Brasil, 2005) e com a Resolução CONAMA no 430/2011 (Brasil, 2011). Mas, no diz respeito aos parâmetros de fósforo e coliformes, estes não apresentaram valores adequados para que efluentes sejam lançados no corpo receptor (Rio Corrente). Conclui-se assim que o tratamento é eficiente apenas em algumas variáveis.

Em se tratando da estrutura da estação de tratamento de efluentes (ETE), do Município de Corrente-PI esta possui um sistema básico, sendo eles o gradeamento, caixa de areia e três lagoas. No entanto, há a necessidade de maiores investimentos na sua infraestrutura, pois no período de coleta a ETE se encontrava com acesso dificultado.

Apesar da ETE possuir uma eficiência na maioria dos parâmetros e ainda conter algumas etapas do tratamento como por exemplo o tratamento preliminar e primário, ela necessitaria de uma estrutura mais complexa, afim de atender toda a população urbana. E ainda seria de suma importância que a cidade possuísse um sistema de coleta separativo no intuito de coletar as águas pluviais e provenientes do esgotamento sanitário, afim de melhorar o tratamento no período chuvoso. Vale ressaltar ainda, que esse monitoramento deve ser realizado ao longo de todo o ano no intuito de verificar a influência da sazonalidade nos parâmetros e consequentemente eficiência no tratamento.

\section{Conflito de interesses}

Os autores declaram não haver conflito de interesses.

\section{Referências}

Barbosa, J. G. Gestão ambiental em estações de tratamento de esgoto sanitário: alternativas para o lodo de esgoto. Revista Especialize On-line IPOG, v. 1, n. 15, 2018. Disponível em: <https://ipog.edu.br/wp-content/uploads/2020/11/jessica-goncalves-barbosa-pagyn12175131614.pdf>. Acesso em: 17 abr. 2019. 
Barthel, L. Lagoas de alta taxa, maturação e aguapés em sistema de tratamento de dejetos suínos: avaliação de desempenho e dinâmica planctônica. Florianópolis: Universidade Federal de Santa Catarina, 2007. (Tese de doutorado).

Brasil. Lei no 9.433, de 8 de janeiro de 1997. Institui a Política Nacional de Recursos Hídricos, cria o Sistema Nacional de Gerenciamento de Recursos Hídricos, regulamenta o inciso XIX do art. 21 da Constituição Federal, e altera o art. 1ำ da Lei no 8.001, de 13 de março de 1990, que modificou a Lei no 7.990, de 28 de dezembro de 1989. Disponível em: <http://www.planalto.gov.br/ccivil_03/leis/19433.htm>. Acesso em: 17 abr. 2019.

Brasil. Resolução CONAMA no 001, de 21 de janeiro de 1986. Disponível em: <http://www2.mma.gov.br/port/conama/res/res86/res0186.html>. Acesso em: 17 abr. 2019.

Brasil. Resolução CONAMA no 357 , de 17 de março de 2005. Dispõe sobre a classificação dos corpos de água e diretrizes ambientais para o seu enquadramento, bem como estabelece as condições e padrões de lançamento de efluentes, e dá outras providências. Disponível em: <http://www2.mma.gov.br/port/conama/legiabre.cfm? codlegi $=459>$. Acesso em: 17 abr. 2019.

Brasil. Resolução CONAMA no 430, de 13 de abril de 2011. Dispõe sobre as condições e padrões de lançamento de efluentes, complementa e altera a Resolução no 357, de 17 de março de 2005, do Conselho Nacional do Meio Ambiente-CONAMA. Disponível em: <http://www2.mma.gov.br/port/conama/legiabre.cfm?codlegi=646>. Acesso em: 17 abr. 2019.

CETESB - Companhia Ambiental do Estado de São Paulo; ANA - Agência Nacional de Águas. Guia nacional de coleta e preservação de amostras: água, sedimento, comunidades aquáticas e afluentes líquidos. São Paulo: Companhia Ambiental do Estado de São Paulo; Brasília: Agência Nacional de Águas, 2016.

Dias, O. D.; Aguiar, F. S.; Tiago, J. P. F. Avaliação da eficiência do tratamento de efluentes líquidos industriais de um abatedouro de bovinos. Anais do XXI Congresso Nacional de Meio Ambiente, Poços de Caldas, 2016.

Esteves, F. A. Fundamentos de Limnologia. 3. ed. Rio de Janeiro: Interciência, 2011.

Gerhardt, R.; Reisdorfer, G.; Cardoso, M. G. Remoção de nitrogênio e fósforo de efluente industrial através da precipitação de estruvita. Tecno-Lógica, v. 22, n. 1, p. 35-40, 2018. https://doi.org/10.17058/tecnolog.v22i1.8858

IBGE - Instituto Brasileiro de Geografia e Estatística. IBGE Cidades. 2010. Disponível em: $<$ https://cidades.ibge.gov.br/>. Acesso em: 3 fev. 2019.

IBGE - Instituto Brasileiro de Geografia e Estatística. Perfil dos municípios brasileiros. 2015. Disponível em: <https://ww2.ibge.gov.br/home/estatistica/economia/perfilmunic/ 2015/>. Acesso em: 4 abr. 2019.

Instituto Trata Brasil. Esgoto. 2018. Disponível em: <http://www.tratabrasil.org.br/ saneamento/principais-estatisticas/no-brasil/esgoto>. Acesso em: 6 jan. 2019.

Mataruco, S. M. C.; Royer, M. R.; Bittencourt, P. R. S.; Peres, W. V.; Mataruco, G. H. Controle de coliformes em efluentes com a utilização de óleo de Eucalyptus citriodorus ou extrato de semente da Moringa oleifera. Revista Conhecimento Online, v. 1, p. 87-107, 2019. https://doi.org/10.25112/rco.v1i0.1527 
Medeiros, R. M.; Sousa, F. A. S.; Gomes Filho, M. F. Análise temporal do balanço hídrico na Bacia do Rio Uruçuí Preto - Piauí. Anais do VI Workshop de Mudanças Climáticas e Recursos Hídricos do Estado de Pernambuco e o III Workshop Internacional sobre Mudanças Climáticas e Biodiversidade, Recife, 2014.

Melo Júnior, A. S.; Bento Filho, R. C.; Papadopoli, G. U.; Morais, A. C.; Hock, L. B. J.; Chirinos, G. J. Avaliação da Demanda Bioquímica de Oxigênio (DBO) em uma lagoa facultativa. INOVAE - Journal of Engineering, Architecture and Technology Innovation, v. 6, n. 1, p. 300-319, 2018.

Pires, D. P.; Silva, F. H. B. T.; Monteiro, C. A. B. Avaliação da eficiência da estação de tratamento de esgoto ETE-Alegria em Teresina-PI. Anais do Congresso Técnico-Científico da Engenharia e da Agronomia, 2015.

RESMC - Relatório de Esgotamento Sanitário Municipal de Corrente. 2017. Disponível em: <http://portal1.snirh.gov.br/arquivos/Atlas_Esgoto/Piauí/Relatorio_Geral/Corrente.pdf>. Acesso em: 10 fev. 2019.

Salgado, S. R. T.; Araújo, A. L. C. Levantamento da tipologia das estações de tratamento de esgoto oriundas do Programa de Aceleração do Crescimento e a previsão do impacto no índice de tratamento de esgoto no Estado do Espírito Santo. Engenharia Sanitária e Ambiental, v. 22, n. 2, p. 293-301, 2017. https://doi.org/10.1590/S1413-4152201694005

Silva, C. O.; Coelho, P. N.; Sá, O. R. Avaliação da eficiência do tratamento de efluentes em um abatedouro do Município de Passos-MG. Revista Nacional de Gerenciamento de Cidades, v. 4, n. 24, p. 13-20, 2016. https://doi.org/10.17271/2318847242420161321

Teodoro, A.; Teodoro, A.; Ide, C. N.; Ribeiro, M. L.; Broch, S. A. O. Implementação do conceito capacidade de diluição de efluentes no modelo de qualidade da água QUAL-UFMG: estudo de caso no Rio Taquarizinho (MS). Engenharia Sanitária e Ambiental, v. 18, n. 3, p. 275-288, 2013. https://doi.org/10.1590/S1413-41522013000300010

Tundisi, J. G.; Matsumura-Tundisi, T. Recursos hídricos no século XXI. São Paulo: Oficina de Textos, 2011.

Informação da Licença: Este é um artigo Open Access distribuído sob os termos da Licença Creative Commons Attribution, que permite uso irrestrito, distribuição e reprodução em qualquer meio, desde que a obra original seja devidamente citada. 